\title{
Erratum to: Tracheal palpation to assess endotracheal tube depth: an exploratory study
}

\author{
William P. McKay, MD · Jim Klonarakis, MD • \\ Vladko Pelivanov, MD · Jennifer M. O'Brien, $\operatorname{PhD}(c) \cdot$ \\ Chris Plewes, MD
}

Published online: 4 July 2014

(c) Canadian Anesthesiologists' Society 2014

\section{Erratum to: Can J Anesth/J Can Anesth \\ (2014) 61:229-234 \\ DOI 10.1007/s12630-013-0079-4}

In the article entitled: "Tracheal palpation to assess endotracheal tube depth: an exploratory study" published in the March 2014 issue, Can J Anesth 2014; DOI: 10.1007/s12630-013-0079-4, Table 3 contained several typographical errors that have now been corrected by the authors. In addition, the first column of Fig. 2 also contained an error that has also been corrected. The authors apologize most sincerely for these errors.

The online version of the original article can be found under doi:10.1007/s12630-013-0079-4.

W. P. McKay, MD (ه) · J. Klonarakis, MD .

V. Pelivanov, MD · J. M. O'Brien, $\mathrm{PhD}(\mathrm{c})$

Department of Anesthesia, RUH, University of Saskatchewan,

103 Hospital Dr., Saskatoon, SK S7N 0W8, Canada

e-mail: bill.mckay@usask.ca

C. Plewes, MD

Department of Radiology, University of Saskatchewan,

Saskatoon, SK, Canada
Table 3 Comparison of tracheal palpation (TP) with measurement method (MM)

\begin{tabular}{lll}
\hline & TP & Calculated MM \\
\hline Number of patients & 92 & 92 \\
Correctly placed $n(\%)$ & $72(78 \%)$ & $57(61 \%)$ \\
{$[95 \% \mathrm{CI}]$} & {$[64$ to 80$]$} & {$[46$ to 64$]$} \\
Incorrectly placed & $20(22 \%)$ & $35(38 \%)^{*}$ \\
Incorrectly placed by & {$[12$ to 28$]$} & {$[26$ to 44$]$} \\
bronchoscopic measurement & $12(13)$ & $34(40 \%) \dagger$ \\
Endobronchial $n(\%)$ & {$[6$ to 18$]$} & {$[25$ to 43$]$} \\
\hline
\end{tabular}

$* P=0.024 ; \dagger P<0.001 . \mathrm{CI}=$ confidence interval

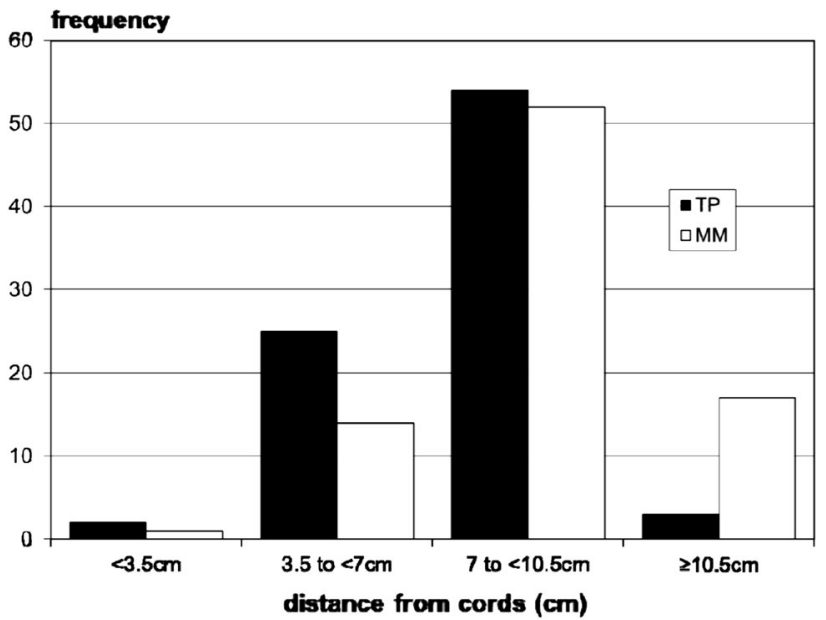

Fig. 2 Frequency histogram: distance of endotracheal tube tip to vocal cords. $X$-axis: distance from vocal cords. Black bars = tracheal palpation (TP) method; white bars $=$ measurement method (MM). $Y$ axis: number of subjects 